\title{
Genetic heterogeneity in duodenal ulceration
}

\author{
A. Venkateshwari, A. Vidyasagar*, N. Pratibha \\ Department of Genetics, Osmania University, Hyderabad - 500 007, and *Gastroenterology Unit, Gandhi Hospital, \\ Secunderabad - 500 003, India
}

BACKGROUND: Duodenal ulcer (DU) is a multifactorial disorder with different etiological and pathogenetic mechanisms. Evidence for the role of genetic factors such as familial aggregation, twin studies, ABO blood groups, $\mathrm{ABH}$ nonsecretor status and hyperpepsinogenemia have been reported in DU. Genetic heterogeneity of cases with familial incidence will provide information regarding the association of qualitative and quantitative traits.

AIM: Hence, the present study is envisaged at identifying the segregant and deviant groups based on parental phenotypes and their association with other quantitative markers.

MATERIALS AND METHODS: 62 out of 462 endoscopically confirmed duodenal ulcer cases were considered for the analysis of genetic heterogeneity. This was resolved through the calculation of genetic risk estimates of sporadic cases in multiplex families based on different modes of inheritance and variation in associated genetic and biochemical markers. RESULTS: Mean age at onset in simplex and multiplex cases was found to vary indicating the presence of genetic heterogeneity in the expression of the disease. Segregant and deviant groups were identified based on mortons probability risk estimates and examined for the possible association of qualitative and quantitative markers such as pepsinogen phenotype, serum and tissue pepsinogen levels, cathepsin E, malondialdehyde and ceruloplasmin levels.

Conclusions: The study thus highlighted the presence of genetic heterogeneity in the expression of the disease. The risk factors associated with segregant type were normal serum and tissue pepsinogen levels increased malondialdehyde levels and association of AC phenotype while the deviant group was characterized by early age at onset with hyper pepsinogenemia and reduced cathepin $E$ levels.

Key words: Age at onset, cathepsin E, deviant families, duodenal ulcer, genetic heterogeneity, pepsinogen, segregant

\section{Introduction}

Genetic heterogeneity refers to the existence of two or more genetically distinct entities with similar clinical features but variations in the mode of inheritance in different families. It can be resolved based on age at onset of the condition, mode of inheritance and variation of associated genetic markers. ${ }^{[1]}$ Duodenal ulcer (DU) is a multifactorial disorder associated with different etiological and pathogenetic mechanisms. ${ }^{[2]}$ Evidence for the involvement of genetic factors in duodenal ulcer includes a) familial aggregation b) twin studies c) association of genetic factors such as $\mathrm{ABO}$ blood groups, $A B H$ non secretor status, hyperpepsinogenemia, HLA antigens etc. ${ }^{[3-6]}$ Hence, heterogeneity in duodenal ulcers (DU) was sought to be resolved through the genetic risk estimates of sporadic cases in multiplex families based on different modes of inheritance and variation in associated genetic and biochemical factors.

\section{Materials and Methods}

462 confirmed duodenal ulcer cases in the age group of 18-74 years, referred to the Gastroenterology unit of the Gandhi Hospital, Secunderabad for a period of four years were considered for the present study. Provisional diagnosis of ulcers was based on clinical symptoms e.g., history of vomiting, belching, bloating, upper abdominal pain etc. Endoscopically confirmed duodenal ulcer cases were considered for the present study. Cases with unclear etiology or cases with associated conditions were not considered for the present study. Information on clinical symptoms, age, duration of the condition, sex, nutritional factors, addictions to smoking, alcohol, consanguinity and familial incidence were obtained from all individuals as per the standard proforma. Blood and mucosal tissue samples was collected from all the patients for the analysis of parameters viz; serum and tissue pepsinogen, ${ }^{[7]}$ cathepsin $E,{ }^{[8]}$ malondialdehyde, ${ }^{[9]}$ 
ceruloplasmin ${ }^{[10]}$ etc. Pepsinogen phenotypes were typed electrophoretically to identify the specific electromorph associated with the condition. ${ }^{[11]}$ The electrophoretic pattern of pepsinogen phenotypes is shown in Figure 1.

Based on the pedigree information, the affected have been grouped into two groups:

a) Familial cases (62) with the incidence of the disease in first and second degree relatives of the propositus which may be predominantly genetic in nature

b) Isolated cases (400) with no family history of ulceration in the members of the family were also considered.

For a given type of parental phenotype ( $\mathrm{N} \mathrm{x} \mathrm{N}$ or $\mathrm{N} \mathrm{x}$ A), the probability of being affected is calculated based on Weinberg's formula of single selection. ${ }^{[12]}$ Genetic heterogeneity if present was identified based on the estimation of probability that a multiplex (a family with more than one affected child) family be of low-risk. If there exist two families, one of which more likely belongs to a low-risk family while the other being high-risk, then we regard that the genetic mechanisms involved in the

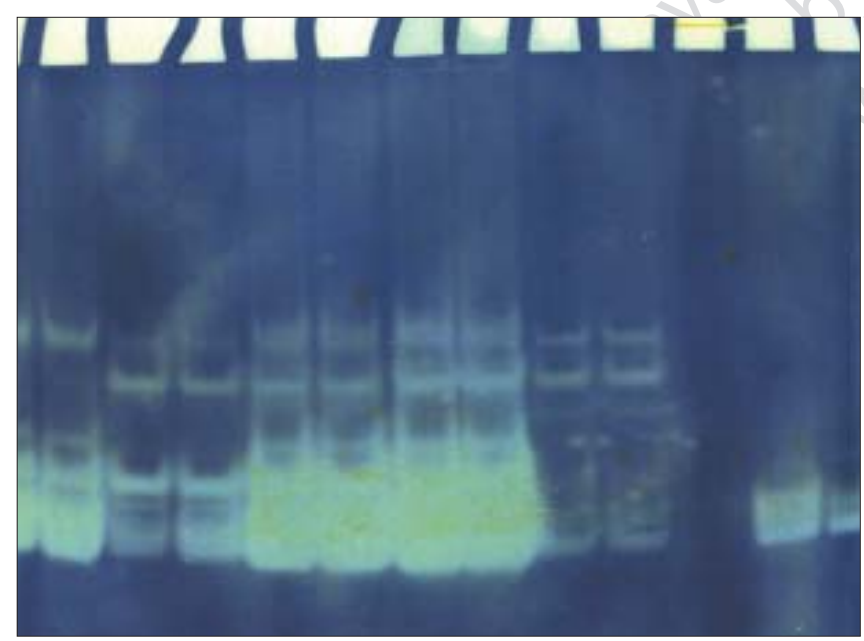

Figure 1: Electrophoretic pattern of pepsinogen phenotypes expression of the disease in the two families may be different. Genetic heterogeneity could be resolved based on the deviations of observed probability from the expected probability over all families of the given mating type and sib ship size. Families showing large deviations from the expected probability may be those, which may be representing a different genetic entity then those showing negligible deviation. Thus two sets of families with probable differences in genetic etiology could be identified. One set having large positive or negative deviation (deviant family) and the second having close to the expected probability as segregant family. It is then examined as to how this type of genetic heterogeneity is associated with the expression of various qualitative and quantitative factors.

\section{Results and Discussion}

An important observation that characterizes genetic heterogeneity is age at onset [Table 1], wherein $52 \%$ of the familial cases exhibited age at onset below 25 years, compared to $24 \%$ of the isolated group with the difference being significant $\left(\chi^{2}-20.43 P<0.01\right)$ statistically. This indicates the greater involvement of genetic component in the etiology of the condition. Mean age at onset in simplex and multiplex cases was found to vary indicating the presence of genetic heterogeneity in terms of the clinical expression [Table 2]. Simplex families of NxA parental type with parental consanguinity expressed the disease earlier (18.0 \pm 2.0 years) compared to multiplex group confirming the involvement of the genetic component in the expression of the disease while multiplex cases (with more than one sib affected) of NxA parental type without consanguinity exhibited early age at onset ( $25.5 \pm 2.5 \mathrm{yrs}$.) than the simplex group without consanguinity. Thus age at onset may be one of the

Table 1: Age at onset of the condition in familial and isolated duodenal ulcer cases

\begin{tabular}{|c|c|c|c|c|c|c|c|c|}
\hline \multicolumn{2}{|c|}{ Age at onset } & \multicolumn{3}{|c|}{ Familial } & \multicolumn{3}{|c|}{ Isolated } & \multirow[t]{2}{*}{ Total } \\
\hline (yrs) & & Males & Females & Total & Males & Females & Total & \\
\hline$<25$ & $\begin{array}{c}n \\
(\%)\end{array}$ & $\begin{array}{c}27 \\
(51.0)\end{array}$ & $\begin{array}{c}5 \\
(55.6)\end{array}$ & $\begin{array}{c}32 \\
(51.6)\end{array}$ & $\begin{array}{c}87 \\
(24.1)\end{array}$ & $\begin{array}{c}9 \\
(24.0)\end{array}$ & $\begin{array}{c}96 \\
(27.7)\end{array}$ & $\begin{array}{c}128 \\
(27.7)\end{array}$ \\
\hline$>50$ & $\begin{array}{c}n \\
(\%)\end{array}$ & $\begin{array}{c}2 \\
(3.7)\end{array}$ & - & $\begin{array}{c}2 \\
(3.2)\end{array}$ & $\begin{array}{c}39 \\
(10.8)\end{array}$ & $\begin{array}{c}2 \\
(5.1)\end{array}$ & $\begin{array}{c}41 \\
(10.3)\end{array}$ & $\begin{array}{c}43 \\
(9.3)\end{array}$ \\
\hline
\end{tabular}

$\chi^{2}(<25$ vs $>25)-20.43^{* *} P<0.01$ 
Table 2: Mean age at onset (years) in simplex and multiplex families based on parental phenotype and consanguinity

\begin{tabular}{lcc}
\hline Parental phenotype & Simplex families $\mathbf{X} \pm$ SE $(\mathbf{n})$ & Multiplex families $\mathbf{X} \pm$ SE $(\mathbf{n})$ \\
\hline Normal x Normal & $30.67 \pm 3.4(11)$ & $32.8 \pm 8.5(18)$ \\
Normal x Affected with consanguinity & $18.00 \pm 2.0(04)$ & $30.5 \pm 8.5(02)$ \\
Normal x Affected without consanguinity & $34.90 \pm 12.0(15)$ & $25.5 \pm 2.5(12)$ \\
\hline
\end{tabular}

criteria helpful in the identification of genetic heterogeneity.

Identification of genetic heterogeneity based on the Morton's risk probability estimates indicated existence of two groups. The deviation between the values for the observed and expected probability of a multiplex family of size 's' being of low risk has been the criteria for identifying the two groups of families. $40.3 \%$ of the families in the present study were found to be segregant while $59.7 \%$ cases observed belonged to the deviant group with a large deviation from expected probability of a particular sib ship size [Table 3]. These two families are then regarded as two entities representing genetic heterogeneity in the expression of the disease.
Segregant and deviant families were examined for the possible association with respect to qualitative and quantitative markers in resolving genetic heterogeneity [Table 4]. 56\% of segregant duodenal ulcer group and $22 \%$ of the deviant families exhibited AC phenotype, which could help in the delineation of genetic heterogeneity associated with the condition. Similarly, the segregant families exhibited normal serum and tissue pepsinogen levels while the deviant families exhibited hyperpepsinogen levels indicating that these two groups may be varying genetically. Thus confirming earlier studies of elevated levels of pepsinogen as a subclinical marker in ulcer diathesis and classification of the duodenal ulcer disease into hyperpepsinogenemic I and

Table 3: Risk probability estimates based on parental phenotype and parental consanguinity

\begin{tabular}{|c|c|c|c|c|c|c|c|c|}
\hline \multirow[t]{2}{*}{ Parental type } & \multirow[t]{2}{*}{$\begin{array}{c}\text { Subship } \\
\text { size }\end{array}$} & \multirow[t]{2}{*}{$\begin{array}{c}\text { No. } \\
\text { affected }\end{array}$} & \multirow[t]{2}{*}{$\begin{array}{l}\text { No. } \\
\text { families }\end{array}$} & \multicolumn{2}{|c|}{$\begin{array}{l}\text { Probability } \\
\text { affected }\end{array}$} & \multicolumn{2}{|c|}{ Low risk prob. } & \multirow{2}{*}{$\begin{array}{l}\text { Deviation } \\
\text { (Obs. - Exp.) }\end{array}$} \\
\hline & & & & Obs. & Exp. & Obs. & Exp. & \\
\hline Normal x Normal & 2 & 1 & 5 & 05 & 0.09 & 0.00040 & 0.00096 & 0.00081 \\
\hline with cansanguinity & 4 & & 2 & C. 25 & 0.09 & 0.00048 & 0.00138 & 0.00091 \\
\hline Normal x Affected & & & 2 & 0.50 & 0.09 & 0.00092 & 0.00057 & 0.00035 \\
\hline \multirow[t]{20}{*}{ without cansanguinity } & 5 & 1 & 1 & 0.20 & 0.09 & 0.00042 & 0.00057 & 0.00015 \\
\hline & & 2 & 1 & 0.33 & 0.09 & 0.00030 & 0.00088 & 0.00058 \\
\hline & 7 & 1 & 1 & 0.14 & 0.09 & 0.00025 & 0.00043 & 0.00033 \\
\hline & & 2 & 4 & 0.29 & 0.09 & 0.00054 & 0.00037 & 0.00026 \\
\hline & 8 & 2 & 2 & 0.25 & 0.09 & 0.00028 & 0.00021 & 0.00007 \\
\hline & & 3 & 1 & 0.38 & 0.09 & 0.00010 & 0.00053 & 0.0004 \\
\hline & 12 & 3 & 1 & 0.25 & 0.09 & 0.000015 & 0.000046 & 0.000041 \\
\hline & 6 & 1 & 1 & 0.17 & 0.20 & 0.00078 & 0.00065 & -0.00013 \\
\hline & & 2 & 1 & & & & & \\
\hline & & 3 & 1 & 0.50 & 0.20 & 0.00024 & 0.00065 & 0.00041 \\
\hline & 3 & 1 & 4 & 0.33 & 0.285 & 0.00042 & 0.000023 & 0.00188 \\
\hline & & 2 & 2 & 0.67 & 0.285 & 0.00141 & 0.00110 & 0.00229 \\
\hline & 4 & 1 & 2 & 0.25 & 0.285 & 0.00011 & 0.000012 & 0.00102 \\
\hline & 5 & 2 & 4 & 0.40 & 0.285 & 0.00220 & 0.000470 & 0.00150 \\
\hline & 6 & 3 & 1 & 0.50 & 0.285 & 0.000250 & 0.00450 & -0.00010 \\
\hline & 6 & 1 & 2 & 0.16 & 0.285 & 0.00091 & 0.000023 & 0.00139 \\
\hline & & 2 & 2 & 0.33 & 0.285 & 0.00011 & 0.000023 & 0.00219 \\
\hline & 7 & 1 & 2 & 0.14 & 0.285 & 0.00040 & 0.000013 & 0.00387 \\
\hline & & 2 & 3 & 0.29 & 0.285 & 0.00011 & 0.000110 & 0.0000 \\
\hline & 8 & 4 & 1 & 0.57 & 0.285 & 0.000055 & 0.00011 & 0.00005 \\
\hline
\end{tabular}


Table 4: Resolution of heterogeneity based on age at onset, pepsinogen phenotype and quantitative variation

\begin{tabular}{lcc}
\hline & $\begin{array}{c}\text { Segregant families } \\
\mathbf{X} \pm \text { SD }(\mathbf{n})\end{array}$ & $\begin{array}{c}\text { Deviant families } \\
\mathbf{X} \pm \text { SD }(\mathbf{n})\end{array}$ \\
\hline Mean age at onset & $34.25 \pm 8.9(25)$ & $28.75 \pm 12.07(37)$ \\
Quantitative variation & & \\
SPG & $238.2 \pm 89.11(25)$ & $317.9 \pm 86.8(37)$ \\
TPG & $1279.9 \pm 404.6(25)$ & $1472.93 \pm 434.43(37)$ \\
CTSE & $58.37 \pm 23.0(25)$ & $47.85 \pm 19.7(37)$ \\
MDA & $306.73 \pm 96.92(25)$ & $324.74 \pm 186.52(37)$ \\
Cp & $21.31 \pm 13.53(25)$ & $22.98 \pm 11.80(37)$ \\
Pepsinogen phenotypes & $\mathrm{N}(\%)$ & $\mathrm{N}(\%)$ \\
AB & $3(12.0)$ & $4(10.8)$ \\
AA & $8(32.0)$ & $12(32.4)$ \\
AC & $14(56.0)$ & $8(21.6)$ \\
BC & - & $2(5.41)$ \\
CC & - & $11(29.7)$ \\
\hline
\end{tabular}

$\mathrm{SPG}=$ Serum pepsinogen (units of pepsinogen $/ \mathrm{ml}$ ), TPG = Tissue pepsinogen (units of pepsinogen/ml), CTSE $=[$ Cathepsin $E(\mathrm{mg} / \mathrm{ml})], M D A=$ Malondialdehyde $(\mathrm{nm} / \mathrm{dL}), \mathrm{Cp}=$ Ceruloplasmin $(\mathrm{mg} / \mathrm{L})$

normopepsinogenemic I types supporting the heterogeneity hypothesis. ${ }^{[5]}$ Similarly deviant group exhibited lower cathepsin E activity compared to segregant group, confirming the role of altered defensive mechanism in ulceration. Thus the two identifiable markers in the resolution of genetic heterogeneity of the condition was found to be quantitative and qualitative variation of pepsinogen and cathepsin $\mathrm{E}$ activity.

\section{Conclusions}

The present study highlights the presence of genetic heterogeneity in the expression of the disease. Mean age at onset in simplex and multiplex cases was found to vary indicating the heterogeneous expression of the disease. The risk factors associated with segregant type were normal serum and tissue pepsinogen levels increased malondialdehyde levels and association of AC phenotype while the deviant group was characterized by early age at onset with hyper pepsinogenemia and reduced cathepin $\mathrm{E}$ levels, strengthening the underlying genetic heterogeneity of the condition.

\section{References}

1. Mousan RR. Familial factors in peptic ulcer, the occurrence of ulcer in relation. Am J Epidemiol 1970;91:453-9.

2. Sleisenger $\mathrm{MH}$, Fordtran JS. Gastrointestinal disease pathopysiology, diagnosis and management. WB Saunders: Philadelphia; 1989.

3. Mourant AE, Koper HC, Sobekaz KD. Blood groups and diseases a study of association of diseases with blood groups and polymorphisms. Oxford University Press: 1978.

4. Clarke CA, Edwards JW, Haddock DR, Howel-Evans AW, Mcconnell RB, et al. ABO blood groups and secretor character in duodenal ulcer: Population and sibship studies. Br Med J 1956;2:725-31.

5. Rotter JI, Petersen G, Samloff IM, McConnell RB, Ellis $A$, Spence MA, et al. Genetic heterogeneity of hyperpepsinogenemic I and normopepsinogenemic I duodenal ulcer disease. Ann Intern Med 1979;91:372-7.

6. Ellis A, Woodrow JC. HLA and duodenal ulcer. Gut 1979;20:760-2.

7. Mirsky IA. Assay of serum pepsinogen. In: Alistair BD, editor. Diagnostic tests in Gastroenterology. Chapman and Hall Medical: London; 1980.

8. Muto N, Yamamoto M, Tani S. Comparative studies of two types of acid proteases from rat gastric mucosa and spleen. J Biochem 1987;101:1069-75.

9. Dahle LK, Hill EG, Holman RT. The thiobarbituric acid reaction and auto oxidation of poly unsaturated fatty acid methyl esters. Arch Biochem Biophys 1962;98:253-61.

10. Ravin NA. An improved calorimetric enzymatic assay of ceruloplasmin. Lab Clin Med 1961;58:161-2.

11. Taggart RT, Miller RH, Karn RC, Tribble JA, Craft M, Ripberger J, et al. Vertical thin layer slab gel electrophoresis of selected human polymorphic proteins. In: Castimpoolas N, editor. Proc Electrophoresis 1978;78:231-42.

12. Emery AE. Methodology in Medical genetics - An Introduction to statistical methods. $2^{\text {nd }}$ ed. Churchill Living Stone: Edinburgh (London); 1980.

Source of Support: Financial support from Lady Tata Memorial Trust, Mumbai and Indian Council of Medical Research, New Delhi is kindly acknowledged.

Conflict of Interest: None declared. 